\title{
Effect of Quail Egg Pretreatment on the Lipid Profile and Histomorphology of the Liver of Acetaminophen-Induced Hepatotoxicity in Rats
}

\author{
Patrick Emeka $\mathrm{Aba}^{1}$, Chiamaka Pearl Eneasato ${ }^{2}$, Jonas Anayo Onah ${ }^{3}$ \\ ${ }^{1}$ Department of Veterinary Physiology and Pharmacology, Faculty of Veterinary Medicine, University of Nigeria, Nsukka, Nigeria. \\ ${ }^{2}$ Department of Biochemistry, Faculty of Biological Sciences, University of Nigeria, Nsukka, Nigeria. \\ ${ }^{3}$ Department of Veterinary Surgery, University of Abuja, Nigeria.
}

\section{ARTICLE INFO}

Article history:

Received on: 13/11/2015

Revised on: 22/12/2015

Accepted on: 16/01/2016

Available online: 19/02/2016

Key words:

Quail egg, Acetaminophen,

Liver damage, Lipid profile.

\begin{abstract}
Quail eggs contain lots of vitamins and minerals that help fight some diseases in the body. Overdose of paracetamol $^{\circledR}$ (acetaminophen) is considered one of the major causes of damages to liver cells. This study was conducted to assess the effect of graded doses of quail egg pretreatment on lipid profile and liver histomorphology of acetaminophen-induced hepatotoxicity in rats. Thirty (30) albino rats were assigned into 5 groups of 6 rats per group. Rats in groups $2-4$ were pretreated with $30 \mathrm{mg} / \mathrm{kg}, 15 \mathrm{mg} / \mathrm{kg}, 7.5 \mathrm{mg} / \mathrm{kg}$ respectively of quail egg solution for 7 days before intoxication with $2000 \mathrm{mg} / \mathrm{kg}$ paracetamol® orally. Rats in group 5 were intoxicated but pretreated with distilled water (DW) at $10 \mathrm{ml} / \mathrm{kg}$ to serve as negative control while rats in group 1 were not intoxicated but pretreated with DW $(10 \mathrm{ml} / \mathrm{kg}$ ) (positive control). Fourty eight $(48 \mathrm{~h})$ hours post intoxication, blood was collected for lipid profile analysis. Thereafter, 2 rats per group were humanely sacrificed and the liver collected for histomorphological examination. The results obtained showed that $30 \mathrm{mg} / \mathrm{kg}$ quail eggpretreated rats (Group 2 rats) had significantly $(\mathrm{P}<0.05)$ lower levels of total cholesterol, low density lipoproten, triglyceride and very low density lipoprotein when compared with that of the negative control. Hepatic histomorphometric results indicate that the vacuolar degeneration observed in all the acetaminophen-induced liver damaged rats were less severe in the liver of group 2 rats. It was concluded that the quail egg pretreatment at the dose of $30 \mathrm{mg} / \mathrm{kg}$ was hypolipidemic and posses hepatoprotective properties.
\end{abstract}

\section{INTRODUCTION}

It has been reported that acute overdoses of Paracetamol ${ }^{\circledR}$ (Acetaminophen) can cause potentially fatal liver damage and its toxicity is the foremost cause of acute liver failure in the western world [1]. Overdose of Paracetamol ${ }^{\circledR}$ leads to 'Paracetamol ${ }^{\circledR}$ hepatotoxicity,' which mainly results into liver injury but it is also one of the most common causes of poisoning all over the world. Many people who develop Paracetamol ${ }^{\circledR}$ toxicity may feel no symptoms at all in the first 24 hours that follow overdose of Paracetamol $^{\circledR}$. Others may initially experience non-specific complaints like vague abdominal pain and nausea [2]. The hepatotoxicity of Paracetamol $^{\circledR}$ is as a result of formation of toxic metabolites when part of it is activated by hepatic

* Corresponding Author

Patrick Emeka Aba, Biochemistry Unit, Department of Veterinary

Physiology and Pharmacology, University of Nigeria, Nsukka,Enugu state,Nigeria.Email: patrick.aba@unn.edu.ng cytochrome p-450 to a highly reactive metabolite- N-acetyl-pbenzoquinonimine (NAPQI) [3, 4]. Liver disorders are global problem. Liver is considered the most important organ for metabolism of lipids, lipoproteins and apolipoproteins under normal circumstances [5]. Most plasma endogenous lipids and lipoproteins are synthesized in the liver and then secreted into the blood circulation [6]. Plasma lipoproteins are mainly catabolized by the liver to maintain the relative balance of lipids and lipoprotein metabolism in vivo [7]. It is documented that liver dysfunction might interfere with lipid metabolism in vivo and could change plasma lipid and lipoprotein patterns [8]. Quail eggs are considered a delicacy in many parts of the world incuding Europe and North America. In Nigeria, the easterners (Igbos) call quail egg "Ogazi egg" and it is a common delicacy cherished in every part of the country. There have been a lot of testimonies about the health benefits of quail eggs including remedy for liver disorders. This study was designed to investigate such claims by the assessment of the lipid profile in acetaminophen -induced liver damaged rats pretreated with varying doses of quail egg solution. 


\section{MATERIALS AND METHODS}

\subsection{Animal}

Adult albino wistar rats of mixed sexes aged 10 to 16 weeks and average weight of $160 \pm 15 \mathrm{~g}$ were obtained from the Animal House of the Faculty of Biological Sciences, University of Nigeria, Nsukka. The animals were acclimatized for the duration of 7 days under standard environmental conditions with a 12 hour light/dark cycle maintained on a regular feed (vital feed) and water ad libitum.

\subsection{Quail Egg}

Quail eggs used were obtained from the Faculty of Veterinary Medicine, University of Nigeria, Nsukka Farm. The freshly laid eggs weighed between $10-15 \mathrm{~g}$.

\subsection{Instruments/Equipment/Drug}

Water Bath (Gallenkamp, England), Chemical Balance (Gallenkamp, England), Conical Flasks (Pyrex, England), Centrifuge (3,500 rpm, PIC, England), Digital Photo Spectrophotometer (EI 312 Model, Japan), Adjustable Micropipette (Perfect, U.S.A.), Paracetamol ${ }^{\circledR}$ (M \&B)

\subsection{Experimental Design}

Thirty adult rats of mixed sexes were assigned to 5 groups of 6 rats per group. The rats were pretreated orally with aqueous solution of quail eggs of varying doses for 7 days. On the $7^{\text {th }}$ day, $2000 \mathrm{mg} / \mathrm{kg}$ of Paracetamol $^{\circledR}$ (acetaminophen) was administered orally. Forty eight $(48 \mathrm{~h})$ hours post acetaminophen administration, blood was collected from the rats for the determination of lipid profile. Thereafter, 2 rats per group were humanly sacrificed and the liver collected for histomorphometric assessment.

\begin{tabular}{cl}
\hline Group & \multicolumn{1}{c}{ Treatment } \\
\hline One & $\begin{array}{l}\text { Pretreated with distilled water + NO Paracetamol intoxication } \\
\text { (positive control) }\end{array}$ \\
\hline Two & $\begin{array}{l}\text { Pretreated with } 30 \mathrm{mg} / \mathrm{kg} \text { quail egg solution }+2000 \mathrm{mg} / \mathrm{kg} \\
\text { Paracetamol }\end{array}$ \\
\hline Three & $\begin{array}{l}\text { Pretreated with } 15 \mathrm{mg} / \mathrm{kg} \text { quail egg solution }+2000 \mathrm{mg} / \mathrm{kg} \\
\text { Paracetamol }\end{array}$ \\
\hline Four & $\begin{array}{l}\text { Pretreated with } 7.5 \mathrm{mg} / \mathrm{kg} \text { quail egg solution }+2000 \mathrm{mg} / \mathrm{kg} \\
\text { Paracetamol) }\end{array}$ \\
\hline Five & $\begin{array}{l}\text { Pretreated with distilled water }+2000 \mathrm{mg} / \mathrm{kg} \text { Paracetamol } \\
\text { (Negative control) }\end{array}$ \\
\hline
\end{tabular}

\subsection{Induction of Liver Damage}

The dose of $2000 \mathrm{mg} / \mathrm{kg}$ of paracetamol $^{\circledR}$ was administered to the rats orally. The quantity given to the rats was calculated thus:

Volume $(\mathrm{ml})=\underline{\text { weight of the rats } \mathrm{X} \text { dose of the drug }}$

$$
\text { Concentration of the drug }
$$

\subsection{Preparation of quail egg}

An empty beaker was weighed (A gm). The shells of the quail eggs were broken with spatula and the contents emptied into the beaker. The weight of the beaker and the contents were recorded as B gm. The weight of the contents of the egg alone was obtained by subtracting the weight of beaker alone from that of the beaker and its contents. Thus the weight of the egg yolk and albumen, $\mathrm{C}$ were expressed mathematically thus:

$$
\mathrm{C}(\mathrm{g})=\mathrm{B}(\mathrm{g})-\mathrm{A}(\mathrm{g})
$$

$\mathrm{C}(\mathrm{g})$ was solubilized in a calculated quantity of distilled water to make a desired concentration of quail egg solution and thereafter, serial dilutions of the stock solution were made for the different groups. The amount administered was equally calculated using the same formula as in the paracetamol intoxication.

\subsection{Blood collection}

Blood samples were collected from the animals using orbital techniques for lipid profile determination. Blood samples were collected from the retrobulbar plexus of the median canthus of the eye of the rats [9]. A microcapillary tube was carefully inserted into the medial canthus of the eye to puncture the retrobulbar plexus and thus enable outflow of about $2 \mathrm{ml}$ of blood into a clean glass tube. The blood was kept at room temperature for 30 minutes to clot. Afterwards, the test tubes containing the clotted blood samples were centrifuged at 3000 revolution per minute using a table centrifuge. The clear serum supernatant was then carefully aspirated with syringe and needle and stored in a clean sample bottle for the lipid profile assay.

\subsection{Determination of Lipid Profile}

The serum cholesterol was determined by cholesterol oxidase-perioxidase method [10]. High density lipoproteins (HDL)-cholesterol concentration was determined by the method of [11] using QCA commercial kit. Estimation of triglyceride concentration was done by method of [12] using QCA commercial kit while Very low density lipoprotein (VLDL) and Low density lipoprotein (LDL) -cholesterol concentration, were calculated using Friedwald formular [13]

\subsection{Histopathological examination}

The histological examination of the tissues of the liver of male albino wistar rats was done using the method of [14].

\subsection{Statistical analysis}

The data generated was analyzed using One-way Analysis of Variance (ANOVA) using SPSS version 20. P values less than 0.05 were accepted as significant. Duncans Multiple Range post hoc test was used to separate the variant means. The results were presented in tables and graphs.

\section{RESULTS AND DISCUSSION}

The wide range of beneficial effects of quail egg such as antioxidant potentials have been credited to the essential nutrients contained in it. These nutrients include: omega- 3 and omega- 6 fatty acids, selenium, choline, folic acid, vitamins such as vitamins $\mathrm{A}, \mathrm{B} 2, \mathrm{C}$, and D; minerals such as magnesium, potassium, phosphorus and zinc [15]. Under normal physiologic conditions, 
liver plays an important role to regulate lipid and lipoprotein metabolisms.

Liver synthesizes and secrets endogenous lipoprotein and key enzymes for lipid metabolism such as lecithin cholesterol acyltransferase and hepatic lipases [16]. It also regulates the catabolism of various plasma lipoproteins via hepatic cellular surface lipoprotein receptors which may maintain relative equilibrium of plasma lipids and lipoproteins in vivo [17]. Examination of plasma lipids and lipoprotein levels will be helpful to evaluate the extent of the hepatic damage. It is well known that plasma levels of cytokines, lipid peroxides and antioxidant status could be changed under acute hepatitis which may interfere with the lipid metabolism in vivo [18].

This study focused specifically on the effect of graded doses of quail egg pre-administration on the lipid profile and hepatic histomorphometry of acetaminophen-induced hepatotoxicity in rats. In this study, the parameters assayed were total cholesterol, triglyceride, low density lipoprotein, high density lipoprotein, and very low density lipoprotein levels. The histomorphology of the liver was also assessed.

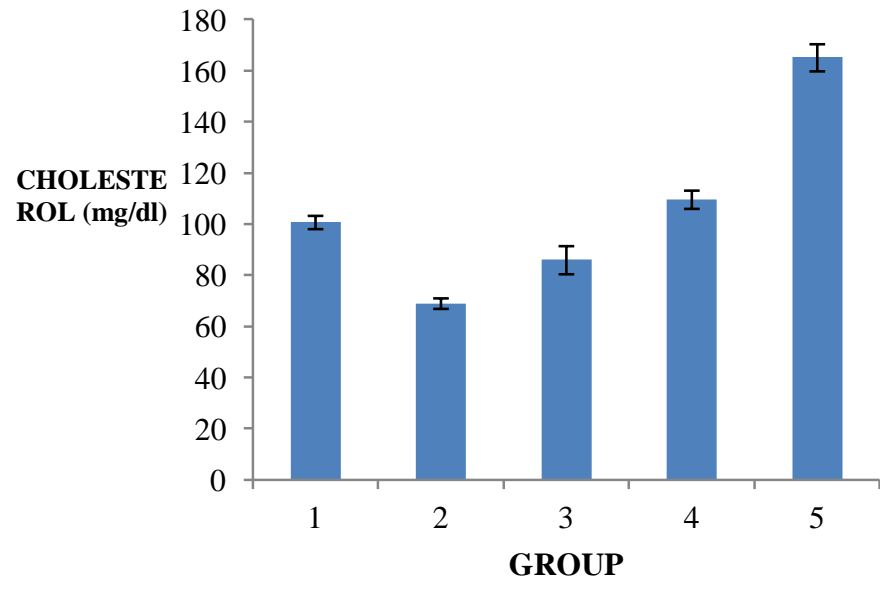

Fig 1: Effects of graded doses of quail egg on total cholesterol level of acetaminophen- induced hepatotoxic rats.

The results showed that the total cholesterol levels of group 5 rats were significantly $(\mathrm{P}<0.05)$ higher compared to that of the other groups. Rats in group 2 recorded significantly $(\mathrm{P}<0.05)$ lower values of total cholesterol when compared to that of the negative control group. The finding of increases in the serum total cholesterol levels of acetaminophen-induced rats is in agreement with the submissions of [19] who reported hypercholesterolemia after induction of liver injury with acetaminophen. Significantly reduced serum cholesterol levels in the quail egg-pretreated rats suggest possible hypocholesterolemic effects of quail egg. The high protein content in the quail egg may have lowered the total cholesterol levels. In the blood, lipids combine with different apoproteins to form lipoproteins that may transfer endogenous or exogenous lipids to different organs or tissue for further metabolism [16].
Table 1: Effects of doses of quail egg on high density lipoprotein level of acetaminophen-induced hepatotoxic rats.

\begin{tabular}{cc}
\hline Group & HDL $(\mathbf{m g} / \mathbf{d l})$ \\
\hline 1 & $43.53 \pm .83^{\mathrm{a}}$ \\
2 & $42.28 \pm 1.25^{\mathrm{a}}$ \\
3 & $35.99 \pm 4.05^{\mathrm{a}}$ \\
4 & $28.27 \pm 3.84^{\mathrm{a}}$ \\
5 & $36.48 \pm 9.87^{\mathrm{a}}$ \\
\hline
\end{tabular}

The result showed no significant difference $(\mathrm{P}>0.05)$ in HDL level among all the groups. They were all statistically comparable $(\mathrm{P}>0.05)$.

Table 2: Effects of the graded doses of quail egg on low-density-lipoprotein level of acetaminophen-induced hepatotoxicity in rats

\begin{tabular}{cc}
\hline Group & LDL ( mg/dl) \\
\hline 1 & $39.37 \pm 4.27^{\mathrm{ab}}$ \\
2 & $14.47 \pm 1.81^{\mathrm{a}}$ \\
3 & $31.78 \pm 0.67^{\mathrm{a}}$ \\
4 & $62.69 \pm 6.77^{\mathrm{b}}$ \\
5 & $107.38 \pm 15.55^{\mathrm{c}}$ \\
\hline
\end{tabular}

The result showed that LDL levels of groups 1-3 rats were statistically comparable $(\mathrm{P}>0.05)$. The LDL level of rats in groups 1 and 4 were also comparable while that of the group 5 rats were statistically higher $(\mathrm{p}<0.05)$ than that of the other groups.It was observed that all the treatment groups had significantly $(p<0.05)$ lower level of LDL compared with the negative control group. Quail egg at all treatment level reduced the LDL levels when compared to the negative control. Increases in LDL cholesterol levels following acute toxic hepatitis had earlier been reported [19]. Quail egg contains the richest variety and mixture of amino acid which can lower serum LDL levels in the blood [20, 21].

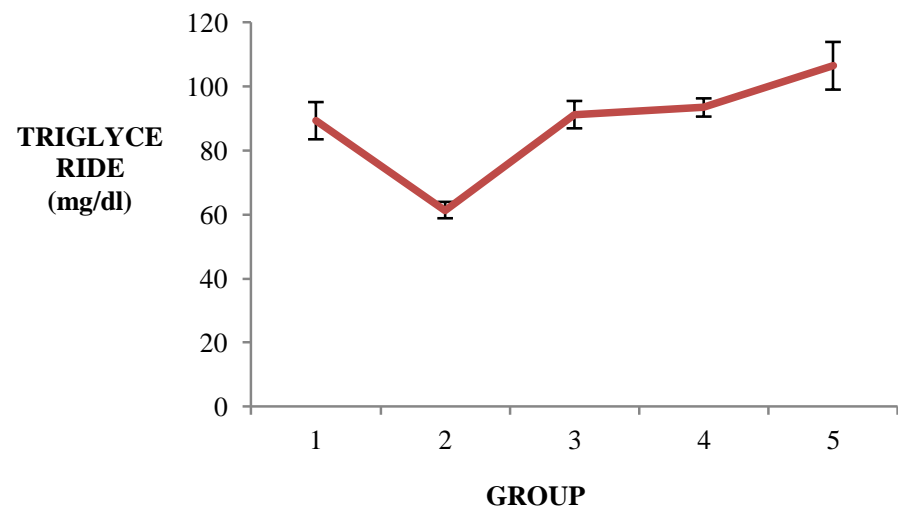

Fig 2: Effects of graded doses of quail egg on the triglyceride level of acetaminophen-induced hepatotoxicity in rats.

It was observed that the triglyceride level of rats in group 5 was significantly $(\mathrm{P}<0.05)$ higher than those of the rats in groups 1 and 2 but comparable with that of the groups 3 and 4 rats. Acute hepatitis is associated with increases in triglyceride levels [22]. The group pre-treated with $30 \mathrm{mg} / \mathrm{kg}$ quail egg (Group 2) recorded significantly $(\mathrm{P}<0.05)$ lower triglyceride levels compared to the negative control group and other pretreated groups. This indicates that the effect was dose-dependent. 


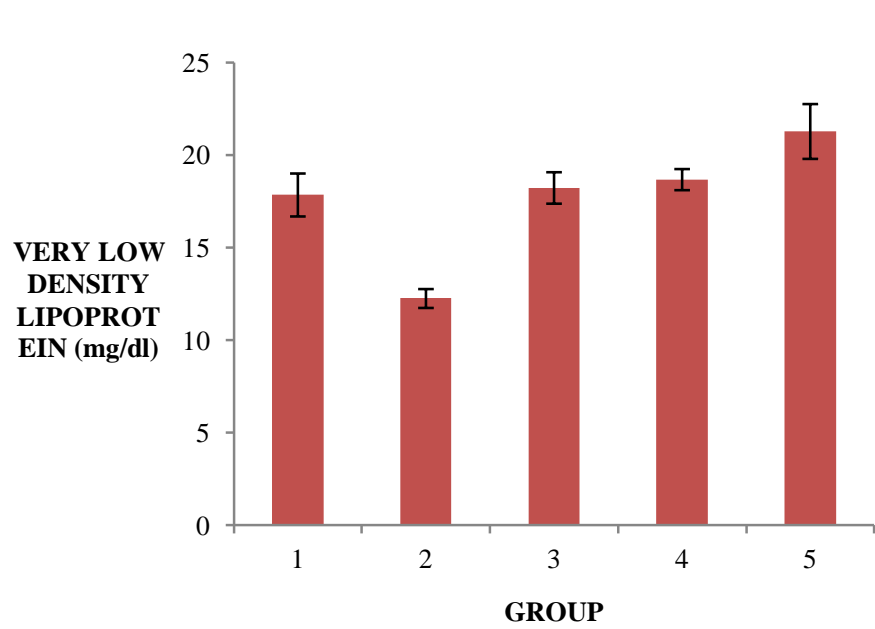

Fig. 3: Effects of graded doses of quail egg on the VLDL level of acetaminophen-induced hepatotoxicity in rats.

It was observed that the VLDL level of group 5 rats was significantly $(\mathrm{P}<0.05)$ higher than that of the rats in groups 1 and 2 but comparable with those of the groups 3 and 4 rats. Increases in the VLDL values of acetaminophen-induced rats is in conformity with the reports of [19] who reported significant rise in the VLDL, LDL and triglyceride levels of rats induced with acetaminophen. From the result, it was observed that the VLDL of the $30 \mathrm{mg} / \mathrm{kg}$ pretreated rats had significantly $(\mathrm{p}<0.05)$ lower VLDL levels compared with the negative control and was comparable with positive control group.

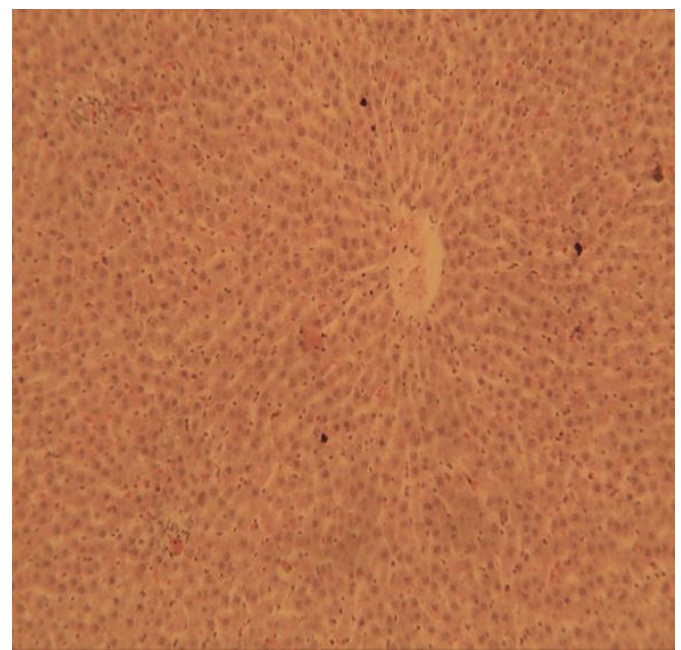

Plate 1: Section showed normal hepatocytes arranged in plaques. Central vein (Arrow). H\&E X100.

It may have achieved this probably because it contains the good kind of fat which improves body function. It is on record that quail eggs contain HDL cholesterol in abundance [23]. The histopathology result showed that the vacuolar degeneration seen in the liver of group 2 rats (pretreated with $30 \mathrm{mg} / \mathrm{kg}$ quail egg solution) appeared milder compared to that seen in the liver of groups 3 and 4 rats.

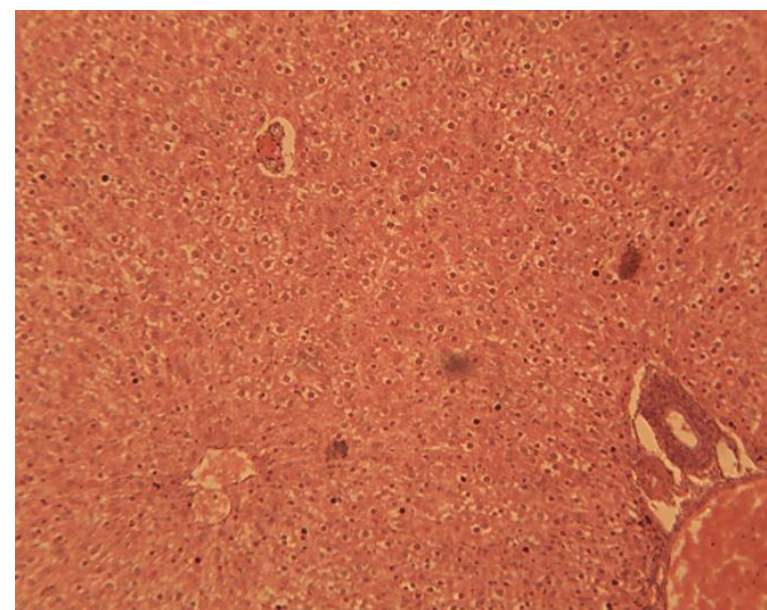

Plate 2: The section showed a moderate vacuolation of the hepatocytes. Central vein $(\mathrm{C})$, Portal area (P), Bile duct (Arrow). H\&EX100.

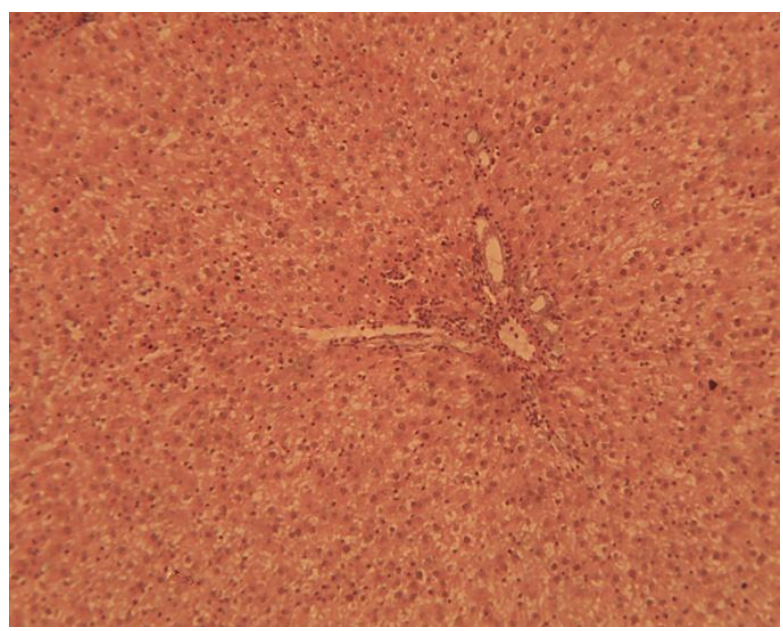

Plate 3: The section showed a severe diffuse cytoplasmic vacuolation of the hepatocytes (Vacuolar degeneration), a mild to moderate, multifocal, periportal aggregation of mononuclear leucocytes and multifocal necrosis with varying amounts of mononuclear leucocytes (Arow).

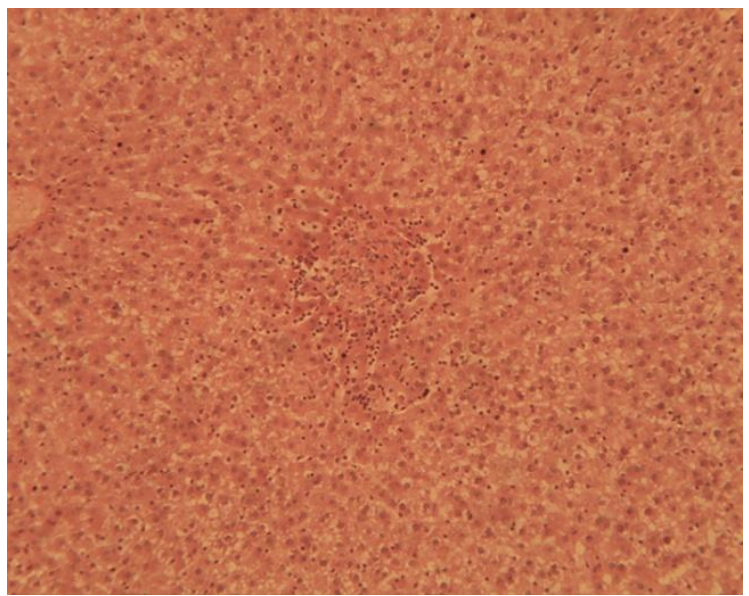

Plate 4: The section of the liver showing a widespread hepatocellular vacuolar degeneration and focal area of necrosis (Arrow) invaded by numerous mononuclear leucocytes; Central vein (C) H\&E X100 


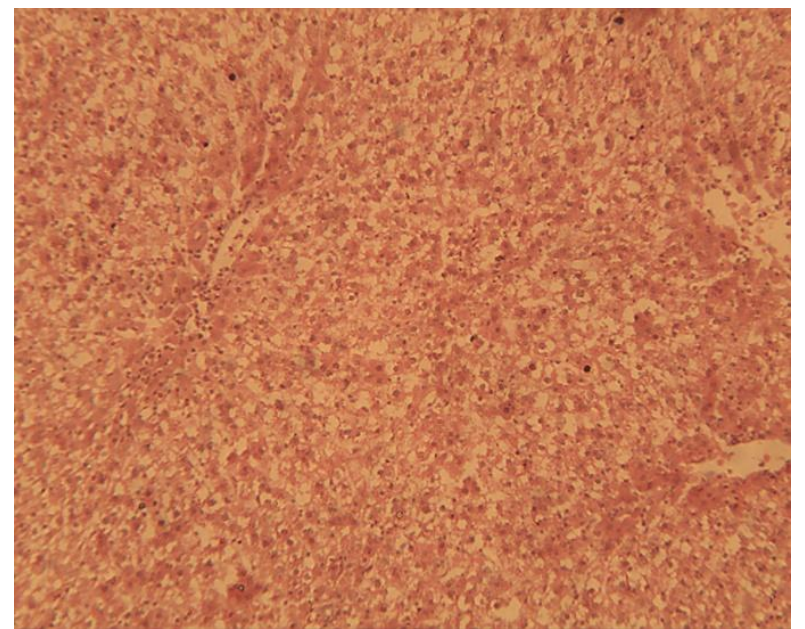

Plate 5: The section shows a varying hepatocellular vacuolar degeneration. It tends to vary from moderate to severe, panlobular to midzonal and periportal, and random. Central vein (C). H\&E X 100.

This implies that at the dose of $30 \mathrm{mg} / \mathrm{kg}$, quail egg was able to mitigate/prevent excessive degeneration and necrosis of the hepatocytes. It has been reported that quail egg, because of its antioxidant properties, can help renew the state of health and combat the degenerative processes in the body [24]. This may have been the mechanism for its protection against excessive hepatocyte degeneration.

\section{CONCLUSION}

In conclusion, pretreatment of rats whose liver were later injured with acetaminophen using graded doses of quail egg solution revealed significant decreases in the levels of total cholesterol, low density lipoproteins, very low density lipoproteins and triglycerides with insignificant effects on the high density lipoproteins. The results of the histomorphological assessment of the liver also showed milder lesions in the quail egg-pretreated groups compared to the distilled water-pretreated. It was therefore concluded that pretreatment of liver-impaired rats with quail egg lead to amelioration of hepatic injury.

\section{REFERENCES}

1. Daly F, Fountain J, Murray L, Graudins A, Buckley N. Panel of Australian and New Zealand clinical toxicologists. Guidelines for the management of paracetamol poisoning in Australia and New Zealand-explanation and elaboration. A consensus statement from clinical toxicologists consulting to the Australasian poisons information centres. Med J Aust 2008; 188: 296-301

2. Rumack B, Matthew $\mathrm{H}$ Acetaminophen poisoning and toxicity Pediatrics.1975;55 (6): 871-876.

3. Vermeulen N.P.E, Bessems J.G.M; Van de Streat, R., Molecular aspects of paracetamol-induced hepatotoxicity and its mechanism based prevention. Drug metabolism"; Rev. 1992;24:367-407.

4. Wallace JL. Acetaminophen hepatotoxicity"; No to the rescue. Br. Journal of Pharmacology 2004;143(1):1-2.

5. Bell AW Lipid metabolism in liver and selected tissues and in the whole body of ruminant animals. Progress in Lipid Research 1979; 18 (3): 117-164

6. Tietge UJ, Boker KH, Bahr MJ, Weinberg S, Pichlmayr R, Schmidt $\mathrm{HH}$, Manns MP Lipid parameters predicting liver function in patients wit cirrhosis and after liver transplantation. Hepato-gastroenterology 1998; 45 (24): 2255-2260

7. Sherlock S. Alcoholic liver disease. Lancet 1995; 345 (8944): $227-$ 229

8. Miller JP Dyslipoproteinaemia of liver disease. Baillieres Clin. Endocrinol.Metabolism 1990; 4(4): 807-832

9. Parasuraman S; Raveendran R; Kesavan R. Blood sample collection in small laboratory animals" J PharmacolPharmacother 2010;1(2): $87-93$

10. Allain, C. C, Poon, L. S., Chan, C. S., Richmond, W. and Fu, P. U. Enzymatic determination of total cholesterol. Clinical Chemistry, 1974; 20: 470-475.

11. Assmann G, Jabs, HU, Kohnert U, Nolte $W$ and Schriewer $H$. Determination of low density lipoprotein (LDL)-cholesterol Clinica Chimica Acta, 1984; 140: 77-83.

12. Albers JJ, Warmick GR and Cheng MC. Determination of high density lipoprotein (HDL)-cholesterol. Lipids, 1978;13: 926-932.

13. Friedewald WT, Levy RI, Fredrickson DS.Estimation of the concentration of low-density lipoprotein cholesterol in plasma, without use of the preparative ultracentrifuge. Clin Chem; 1972;18:499-502

14. Drury RA, Wallington A and Cameroun SR. In Carlleton's Histological Techniques. Oxford University Press, New York. $1967 ; 1-420$

15. Troutman. What Are the Benefits of Quail Eggs? http://www.ehow.com/list_6671158_benefits-quail-eggs_.html Accessed 9th 2012.

16. Pangburn SH, Newton RS, Chang CM, Weinstein DB, Steinberg D, Receptor-mediated catabolism of homologous LDL in cultured pig hepatocyte. The Journal of Biological Chemistry 1981; 256 (7): 3340-3347

17. Booth S, Clifton PM, Nestel PJ Lack of effect of acute alcohol ingestion on plasma lipids. Clinical Chemistry 1991; 37 (9):1649

18. Peterhaus E. Reactive oxygen species and nitric oxide in viral disease. Biol. Trace Elem. Res 1997; 56(1):107-116

19. Hanumantha RBR, Arumugam S, Thiruvengadam D Effect of Sargassum polycystum (Phaeophyceae)-sulphated polysaccharide extract against acetaminophen-induced hyperlipidaemia during toxic hepatitis in experimental rats. Molecular and Cellular Biochemistry 2005; 276 (1): 89-96

20. Brier J. Abundance relative gelatin activity and distribution of the 95,000 dalton acting-binding protein from Dictyostellum discoideum. Journal cell biology 1983;97:178-185

21. Varghese JS, Krishnaprasad K, Upadhuyay R, Revathy MS,Jayanthi V. Lipoprotein profile .cirrhosis of Liver. European journal Gastroenterology Hepatology .2007;1:41-45

22. Luo L, Pu X, Wang Y, Xu N. Impaired plasma lipid profile in acute hepatitis. Lipids in Health and Disease 2010; 9(5): 9-5

23. Living healthy Benefits of Quail egg. a-livinghealthy.blogspot. com/2012

24. Bernard Launois and Glyn G. Jamieson. The Posterior Intrahepatic Approach in Liver Surgery, Land Bioscience and Springer Science+Business Media; 2013.

\section{How to cite this article:}

Aba PE, Eneasato CP, Onah JA. Effect of Quail Egg Pretreatment on the Lipid Profile and Histomorphology of the Liver of Acetaminophen-Induced Hepatotoxicity in Rats. J App Biol Biotech. 2016; 4 (01): 034-038. DOI: 10.7324/JABB.2016.40106 